\title{
INTERNAL CHANGE AGENTS' VIEW OF THE MANAGEMENT OF CHANGE PROBLEM
}

(Published in the Journal of Organizational Change Management, 2003, 16: 480-496)

\begin{abstract}
\end{abstract}
The vital importance of change management in today's competitive climate has been widely investigated. While the need for successful change management is intensively proclaimed by 'expert' consultants, the response for some time has been regarded as falling short of what is required. The heavy emphasis in the literature on a rational-linear approach to understanding organisational change overlooks the significance of the cultural and political dimensions of organisational life. This article highlights a systemicmultivariate view of change by investigating internal change agents', that is managers', accounts of the barriers to change management. It addresses the limitations of change management by attending to the perceptions of managers, that is those actors who generally determine organisational priorities and make crucial resource allocation decisions. This article illustrates the systemic line of thinking adopted by managers undergoing major restructuring efforts in their organisations. This line of thinking is shown to differ from the espoused values of managers that constitute the rational-linear view of change management.

Keywords: change management, rational-linear view, systemic-multivariate view, internal change agents

\section{INTRODUCTION}


The field of organisational change is one ripe for a critical setting of competing views. "One of the main boundaries in this broad terrain is the one which separates the modelbuilders from recipe-givers, the theoreticians from the practitioners" (Buchanan, 1993:684). The recipe-givers, who ascribe to the large consulting firm model of change (e.g. Miles, 1997), are seen as advocating the rational-linear view of organisational change, whilst the model-builders are perceived as supporting the systemic-multivariate view of organisational change (e.g. Cooperrider and Bilimoria, 1993; Marshak, 1993). It is commonly observed among the advocates of the rational-linear view of organisational change that there is an optimum solution for organising labour, raw materials and capital and for adopting new organisational practices (e.g. Church et al., 1994). Within this view, the focus has been primarily on the contingencies necessary for the success and effectiveness of implementing organisational change. Situational models of contingencies, under which different approaches to change assume one-best-way across business contexts or timescales (Kotter, 1995; Tushman et al., 1997), present an ideal model of what happens in organisations at different points in time or in different contexts. Although a contingency approach to organisational change has encouraged practitioners to consider aspects of their environment, technology and size as a basis for deciding on the appropriate paths of change, it delineates deterministic assumptions about the nature of change in organisations, presents inadequate appreciation of the role of strategic choice, beliefs and power and neglects the fact that organisations are collections of diverse interests (Dawson, 1996). There is much research reporting on implementation of change programmes where the resulting picture is far from a replica of discrete set of 
economic, structural and technological contingencies (e.g. Senge, 1990; Pettigrew et al., 1992). Thus, there is evidence to suggest that universal prescriptive models of change management are inadequate to describe the diversity of approaches actually used by organisations (Dunphy and Stace, 1993).

To date, investigations have largely focused on the identification of critical variables that might better explain how organisational change can be managed to the best effect (e.g. Kanter et al., 1992). While not denying the worth of these investigations, this paper reports on a study that highlights a systemic approach to understanding organisational change. It aims to draw upon managers' accounts of change management in order to gain a richer insight into the sources of the apparent problem with the management of organisational change. In particular, the aim is to understand how managers themselves understand the meaning and priority of change management, and the ways in which they explain the characteristics that facilitate or inhibit the process. This can shed light upon the reasons for the apparent mismatch between exhortation and action. In contrast to studies that have pioneered the way (e.g. Weick, 1995; Carnall, 1995), this paper develops a systematic approach to understanding the barriers to change management by empirically highlighting the critical line of thinking adopted by managers in launching organisational change. It sets out to examine the issue of change management by viewing it through the eyes of the participants most critical to the process, that is the managers themselves, the people who establish priorities, devise strategies, control resources, and manage performance. In this respect, managers constitute internal change agents that shape the conditions for change (Hartley et al., 1997). They hold views and 
visions that often conflict with established mental models hence fail to be put into practice. In line with this conceptualisation, the use of the term 'internal change agents' refers to managers rather than internal consultants all throughout the paper. As Hartley et al. (1997:62) argue, "the literature is less informative about those who try to develop change from within the organisation". Such change agents may be senior line managers or those specifically charged with managing the processes of organisational development and cultural change in the organisation. Unlike the definition that is commonly adopted, for instance, by US firms, internal change agents in the cases reported here do not necessarily have the skills and knowledge in change theory or change processes.

The paper is organised into three sections. The following section draws on the existing literature in order to identify what and how much is currently known about the problem of change management. This discussion also incorporates the role of change agents in dealing with change. The third section reports on a recent study drawing on interviews in two case companies in order to explore what can be revealed through paying careful attention to the insights of key players in change. The final section analyses the implications of the findings.

\section{LIMITATIONS IN CHANGE MANAGEMENT}

\section{The Challenge to Rationality}

What faces those charged with bringing about changes in organisations is much more of a mess than a difficulty. There is evidence to suggest that the universal, prescriptive model 
of change management is inadequate to describe the diversity of approaches actually used by organisations (Dunphy and Stace, 1993).

Some seek to restrict the meaning of change management to the felt need to improve organisational performance and members' own position within the organisation (e.g. Goodstein and Burke, 1991). Dawson (1996) has discussed the limitations of adopting such a simple definition of change. She sees conflicting interests and resistance as some of the barriers to achieving the desired results in the felt need for change. Other researchers (e.g. Tichy, 1983) acknowledge the frustration that managers feel when their organisations do not respond to elaborately analysed plans, where there is a lack of interaction between decision and action.

In contrast to the rational-linear view embedded in the traditional approach to change, there are those who perceive change management as a systemic process incorporating systems of interpretation and meaning (e.g. Hassard, 1991; Knights and Willmott, 1995). This view is particularly important, as it emphasises the social aspects of exchange through which the locus of knowledge and the understanding of 'real' things is subjectively shared and shaped by individuals through conversation and dialogue. What is seen as real is made real through sense-making processes (Weick, 1995), and "the social world is best understood from the viewpoint of the participant-in-action" (Hassard, 1991:277; see also Hammond, 1996 on 'appreciative inquiry' where the organisation is seen as a mystery to be embraced). In an empirical sense, this perception of change management reflects the management of processes through liberal exchange of 
knowledge, building of trust and acknowledgement of the heterogeneity in values, preferences and interests.

In spite of the attention that the management of change has received, organisations continue to have problems in managing organisational change and "the search for generalised laws of change still pervades the discipline" (Wilson, 1992). There is a gap between what the rational-linear change management approach prescribes and what change agents do. It is suggested in this paper that one possible source of this gap can be revealed by the way change agents perceive and interpret the issue. Hence, close attention is paid here to change agents' perceptions of the nature of the organisational change process.

\section{The Role of the Change Agent}

The success of implementing change is generally associated with those who facilitate the change process. The change agent is defined here as a manager who seeks "to reconfigure an organisation's roles, responsibilities, structures, outputs, processes, systems, technology or other resources" in the light of improving organisational effectiveness (Buchanan and Badham, 1999:610).

The role of change agents as facilitators is extensively discussed within a rational framework. For example, Buchanan and Boddy (1992) list competencies of effective change agents as clarity of specifying goals, team building activities, communication skills, negotiation skills and 'influencing skills' to gain commitment to goals. It can be 
deduced from these arguments that limitations in change management are associated with the managerial perceptions of the need for change, the opportunity to change and about the way to change. This renders perceptions, beliefs and assumptions of change agents as vital aspects to be understood.

With a few notable exceptions (e.g. Ackoff, 1993), managers are commonly projected as ignoring the complex and multivariate nature of reality. However, as the OD researchers such as French and Bell (1990) advocate, managerial preferences, normative patterns and political contingencies can affect the process of change. The degree to which change agents can find a balance between "being the 'technical' expert—-the person assumed to have the answers - and the process facilitator-the person with the techniques to allow the organisation to find its own answers" (Paton and McCalman, 2000:197) is questionable in the light of the following: diversity of values and interests, politicised and value-driven decision-making process, subjective interpretation of information and the role of norms and cognitive schemes in change efforts.

In practice, most managers are problem-resolvers who do not pretend to be objective in their decision-making. They justify their conclusions by citing lack of time or information or the complexity of a situation (cf. Senge et al., 1999). Organisational members who are not only potential change-makers but also recipients of organisational change are likely to be more questioning about the value of change. Thus, it is suggested here that an exploration of social dynamics at play that reflect the constitutive and regulative rules or normative expectations from the standpoint of internal change agents 
is needed. The next section describes how the task of examining internal change agents' perceptions on the process of managing change was carried out.

\section{RESEARCH METHODS AND SITES}

Given the research objectives of this paper, a close access to the perceptions and cognitions of an array of managers was needed. Qualitative research employing theme analysis was deemed appropriate to put managers' perceptions into context. There was a search for patterns or systematic units of cultural meaning in relation to change management (cf. Boje, 2001). Field studies were carried out in an engineering firm, Samson, and a training organisation, Metis (both pseudonyms), which were undergoing radical change programmes at the time of data collection. The firms were selected on the basis of their current experience in major structural and cultural change efforts. Samson was delayering in an attempt to reduce redundancy, having recently been acquired by a large foreign company, Leto (also a pseudonym), between 1994 and 1996. Whereas, Metis was working with a consultancy group to internalise new cultural dimensions in the organisation, having experienced a merger in 1996. Access was granted on the basis of an interest on the part of the companies in an independent inquiry into the progress of the ongoing organisational change efforts. In other words, entry into the two firms was secured as a researcher rather than a consultant. It was agreed that a report detailing the perspectives of various actors on the facilitators and inhibitors of change efforts would be produced to serve as a progress check on the ongoing change programme. In addition, the gatekeepers were familiar to the researcher through their enrolment on the same postgraduate programme at an academic institution. The key issues arising during negotiation 
of access were as follows: the benefit which could be offered to the organisation (in this context, the feedback on the research findings), the amount of organisational time the research was likely to take, and the extent to which the research findings would become public through publications. Eventual publications were agreed to on the basis that the identity of the organisation was disguised and the anonymity of individuals preserved. Respondents were informed of the purpose of the research and were given assurances of the anonymity of their answers.

The field research drew on document analysis and 20 interviews -14 at Samson and six at Metis in the UK - conducted by the researcher between November 1998 and January 1999. Data were derived from semi-structured interviews with senior- and middle-level managers.[1] All of the 14 participants interviewed at Samson, with the exception of two engineers, were project managers. These managers were selected from the electrical design, sales and marketing, IT, quality control, computer audit, human resources, environmental programmes, and engineering departments. At Metis, all of the six participants, including the Chief Executive, were senior-level managers from the finance, IT, standards development, regional training, and product management functions. Thus, the respondents were selected on the basis of their position in the organisation and the department of affiliation. The aim of the inquiry was to reveal the different truths and realities held by different individuals across sections within a firm. Making explicit the procedures that had been followed for data collection enhanced the reliability of the research results. These procedures included matters of interview protocol, taperecordings of interviews and the feedback on transcriptions from the participants. A valid 
picture of the researched phenomenon was attained through theoretical saturation (see Glaser and Strauss, 1967, for a definition).

The research addressed the matter of respondent bias by triangulating data. Multiple sources of confirmation were necessary to clarify meaning and to verify the repeatability of an interpretation. Data were drawn from interviews and document analysis. Moreover, within the case companies, interview data with a particular work group were checked against responses from another group. For example, group development managers' accounts at Samson were triangulated with project development and design managers' accounts.

The interviews were semi-structured to attain flexibility in probing issues deeper, as well as consistency across responses so that a basis for comparison was established. Participants were given the flexibility to express their views with open-ended questions. 'How' and 'why' questions were asked about managerial attitudes to organisational change. The challenge here was to understand and interpret complex forms of social activity, which were defined by the actors themselves in terms of their own subjective meanings.

Each interview lasted on average one hour and was tape-recorded, with the exception of three Samson members (IT manager, Personnel Manager and Quality Engineer) who did not wish to be recorded. The content and format of the interviews were as follows: participants' role within the organisation, their work history and understanding of the 
factors that facilitated and hindered change, the decision-making process, means of dealing with uncertainty and complexity, and the learning process in the organisation.

To achieve high-quality analysis, collected data were coded and analysed. During the coding process, interview transcripts were analysed through the categorisation of emergent concepts and ideas (Huberman and Miles, 1998) and constant comparison of these concepts in order to identify common themes. Interview notes were organised across informants according to key components of the interview guide. Some of the emerging themes in the process included flow of information, work attitudes, organisational structure and political processes. These preliminary themes and topics were then analysed and aggregated to arrive at a set of topics that were commonly recurring. Initial analysis revealed themes such as gender related concerns over female representation on committees to be of indirect relation to change management in the early stage of data analysis. All data were then re-studied and re-categorised in terms of new set of common themes. The interpretation of empirical data was furthered through discussions with research participants. Company reports circulated for feedback served to validate research results. The iterative analysis of data and themes allowed for the emergence of the tension between espoused values and values-in-practice that were grounded in actors' experiences and interpretations.

Samson, a large engineering firm with major investment programmes in advanced design and engineering techniques was established at the beginning of the $20^{\text {th }}$ century. Upon its acquisition by an overseas company (Leto), Samson confronted a strikingly different 
culture that required a new set of procedures to follow. Since its acquisition, Samson has been in a process of continual investment to push the limits of technology and innovation addressing its key processes and structures to instil a new organisational culture.

Metis was a medium-sized (i.e. 200-499 employees) training organisation for UK engineering manufacture sectors. It was formed through the merger of two training bodies that felt the need to benefit from synergistic effects of complementary skills. These bodies played a significant role in fostering the skills needed in the engineering industry and had been working closely together on the development of occupational standards. Management believed that the merged organisation had a stronger representational voice and improved cost-effectiveness with wider staff expertise and significant amount of inherited capital. The two training bodies experienced the same problem of a clash of cultures as had Samson's. This problem was claimed to stifle the transition, or in Bridges' (1995:3) terms “the psychological process people go through to come to terms with the new situation", to a more commercially oriented culture at Metis. Although Samson and Metis had significant differences with regard to their size and resources, they were both confronted with similar organisational change issues. Both organisations launched a structural change with the aim to eliminate redundant work, and a cultural change where members were trained to plan for improvement. The Leto board was driving change efforts at Samson, whilst at Metis, senior management (with the assistance of an external consultant) provided the impetus for change. Change at both companies had been triggered by a stakeholder move-an acquisition in the case of Samson and a merger in the case of Metis. In other words, in both cases, the organisation 
that was economically more successful set the direction for change. At Metis, the training association's commercial success was predominantly more influential in setting the change agenda than the financial circumstance of the bulky training authority.

The research findings show that even though internal change agents espouse change management styles to be participative, free from politicking, involving all-concerned in decision-making and diverting resources to solving actual, operational problems, as well as incorporating shared systems of meaning and structure of discourses, they admit to a set of cultural and political assumptions that are at play in change efforts in practice. The next section presents change agents' account of the tension between the espoused values and the values-in-practice that has an impact on the management of organisational change.

\section{THE TENSION BETWEEN THE RATIONAL-LINEAR AND SYSTEMIC- MULTIVARIATE VIEWS OF CHANGE}

The research findings reveal information on the understanding of internal change agents' meaning of change management to shed light upon reasons for persistent problems with change implementation. The analysis of responses by change agents reveals two sets of perceptions. The first set relates to a rational-linear view that was offered by the change agent as an ideal state. The second set of assumptions reflects the conversion from a rational-linear view to a systemic-multivariate view in change agents' efforts to come to grips with the actual business situation. This points to learning in change agents' assumptions as to how change can be implemented. 


\section{The Rational-Linear View}

In line with the classic argument on 'environmental determinism' (e.g. Burns and Stalker, 1968), change in organisations is perceived by internal change agents in this study as being triggered by change in environmental conditions such as competitive pressures, legislation, environmental and safety regulations, world-wide economic threats, key stakeholders and leadership preferences and technological advancements. However, the wider political struggles to gain control over scarce resources emerge as the most powerful stimulator of change. As far as the cases are concerned, considerable time is invested into building relationships to this end. For example, a manager in Environmental Programmes at Samson contends "we are trying to influence the way law is written. You can call it lobbying". Similarly, a project manager in Training at Samson claims that "power centres determine whether change will happen or not".

Unity in goals and full participation in change efforts, despite the fact that such participation may not generate a complete agreement on various aspects of the change process, are seen as desirable conditions for effective implementation of organisational change. These espoused values reflect a “'unitary' frame of reference which emphasises the philosophy that organisations have goals to which all organisational members subscribe, with all working towards their attainment" (Senior, 1997:167). The need for united efforts is exemplified by the need for integrated systems and change initiatives. For instance, Samson "is an organic organisation with small pockets of separate growth" (IT Manager). Its activities are not integrated and its members discuss change-related matters in isolated groups. People either do not recognise or choose to ignore the fact that 
inter-dependency of organisational systems results in change in one area to have an impact on change in another area further down the system. There is a need for a structured process whereby communication can take place on a timely basis (Samson engineer). At Samson, a common engineering system for sharing parts, as that at the parent company, does not exist. The extent to which the influence of Leto is felt by different units within Samson varies due to a lack of integration or the presence of small islands of activity. The variation in standards, the IT network link and 'culture'[2] across Samson sites hinders the creation of a unity of purpose. The most successful site is seen as accommodating highly focused teams that are cherry-picked or selected as being the best. The concerned site's budget is more carefully controlled. Financial success in this context is defined in terms of a 'positive' culture, that is a sense of commercialism, where proactivity, time management and customer focus are considered as crucial for success. Commercial success, which is measured mainly in terms of financial criteria, breeds 'mimic what we do' rationale at Samson. In other words, there is the belief that contingencies necessary for an effective implementation of organisational change can be transplanted with ease to another context (e.g. Goodstein and Burke, 1991). This is evident in Leto's efforts to change the organisational structure at Samson to resemble that of the parent company.

A related managerial conception to creating unity of purpose is the idea of reducing resistance to change. It is hoped at Samson and Metis that this can be achieved through open, reliable communication, formation of trust and participation in joint activities where learning can be valued and shared across functions by all hierarchical levels (cf. 
Schein, 1993). Sharing of knowledge in this context is seen as essential for effective performance, and scientific method is perceived as the ideal way to explore that knowledge.

Internal change agents idealise a rational decision-making process detached from politics, citing as a reason their continual confrontation with politicking in practice. The divergent interests of stakeholders within and outside organisations influence decision-making, as advocates of the systemic-multivariate view of organisational change (e.g. Dawson, 1996) argue. In line with the preference for rational decision-making, change agents perceive a need to measure performance against tangible standards. This is noticeable in the efforts of Samson and Metis to tie learning exercises within change programmes to measurable outcomes. For example, learning is associated by the 'hard core' people at Samson such as the engineers with technical training. For them, being close to the product is a means of learning more. "There is a direct correlation between how close the group is to delivering the product and learning" (Design Manager at Samson). It is claimed that change regarding a tangible output, such as a capital investment or a new building, is easier to bring about than change concerning an intangible output, such as the degree of learning. This is because procedures that guide actions in the case of tangible product changes are seen as more codifiable than those for tangible outputs (cf. Nonaka and Takeuchi, 1995). There is an extensive difference in the way change management is perceived between managers having administrator roles and engineers reflecting the nonlinear, quasi-rational nature of change. Administrators are seen by some of the engineers as heavily embedded in politics and detached from actual change. For instance, the 
reason why the engineering team would be asked to work overtime for two hours on Friday afternoons was not clear until the engineers discovered that the Apollo board visited Samson on Fridays. Politics seem to drift people away from the actual problems. "There is a reality gap...too much politics and not getting on with the real issues. People in ivory towers see through rose-tainted glasses" (Manufacturing Manager at Samson). In other words, top management/administrative levels are seen as wasting resources on politicking and detaching themselves from solving the 'real' problems at the production level.

The need for a greater degree of structure, clarity and formality is especially felt in times of economic difficulty. For example, at Metis, there is a desire to instil confidence in organisational members to keep pace with change in the efforts of change agents to move towards greater adaptability and flexibility. It is hoped that this can be achieved with a clear structure to the change agenda. A senior manager at Metis argues that benefits need to be clear and measurable. "We have our fingers in too many pies. We track added work just because it might be related [to the core business]" (Product Manager at Metis). Further example can be provided from Samson. "There is a lack of clarity in Samson's objectives. Things could be better with clearly defined directives rather than small fragmented initiatives" (Design Manager). The analysis of responses of the way change is managed in practice reveals striking contrasts with the prescriptions representing idealised contingencies. The following section provides an account of the systemicmultivariate view of change agents in action. 


\section{The Systemic-Multivariate View}

The notable result across the interviews as a whole is the extent to which internal change agents display a systemic-multivariate perspective in coming to terms with the reality of change. Samson and Metis members acknowledge the heterogeneity of interests, importance of stakeholder and networking efforts, bounded rationality of actors in decision-making and the exercise of symbolic or indirect control through the use of language. There is evidence to suggest that intuition is widely used in decision-making. Organisational members do not have the capacity or the resources to "account for every possible hiccup [i.e. complication]. One cannot collect all the information available in the environment" (Electrical Design Manager at Samson). The Samson case shows that the means of coping with the environment calls for selectivity in information processing. Similarly, Metis members resort to intuition to prioritise large number of issues. "Complexity makes it difficult to integrate different islands of activity. Heads of departments are not aware of all the inter-relationships. It is not very effective to cover every aspect. You cannot tackle all” (Regional Manager at Metis). This finding is in accordance with Dawson's (1996:241) argument that “organisations accommodate irrational, creative and intuitive aspects of cognition and behaviour".

Change can also incorporate symbolic manifestations. Discourse like any other resource, is a potential tool that can be used for initiating change (Reed, 1992). Sturdy and Morgan (2000) argue that organisational change constitutes discourses that establish a set of rules and procedures about what is legitimate to say and do in specific contexts. Contexts can be shaped by the use of new words and the elimination of old words. For example, 
General Electric's shift from a mechanistic to a relatively organic organisation in the 1980s represented a pervasive change in what members recognised as facts and legitimate forms of action. New symbols were created for the new context. Leaders shaped the context within which members dialogued by introducing new words such as 'teamwork', 'participation' and 'delegation'. The new activity was legitimised as a different set of words emerged. At Samson, it took the human resources group 12 months to encourage its organisational members to internalise the meaning of the word 'competence'.

Previous 12 months of wrestling with these concepts and arguing over things...people were actually discussing them back at their place. These concepts had leaked out. In the 12 months of discussion, people had been talking about it. Because they have been through it, they were sure of it and started to use it. (People Development Manager at Samson)

New words were effectively legitimised through the passage of time. Once people were certain of the consequences of change, they took comfort in using new symbolic manifestations.

The heterogeneity of preferences contributes to a mismatch between exhortation and action. The Chief Executive of Metis points to a divergence in interests and the likely emergence of a conflict. 
There are some of the old soldiers of the very old days. There are some soldiers who have seen the benefit of change and are supporting me, and there are increasingly new people whom I am bringing in as fast as I can from the industry who have a totally different attitude. And I have inherited a number of people through our merger. So there is a great mix of cultures throughout.

It is interesting to note here the use of the metaphor 'soldier'. It reflects a particular understanding of the role of organisational members in change (cf. Marshak, 1993). Metis is seen by the CEO as an 'army' that is expected to operate as a single-voice in a predictable and efficient manner. The metaphor points to a centralised command structure at Metis where resistance to change can be understood in terms of disobedience to a central authority figure. The role of a change agent in this context would be to restore order in the 'army'. The interests of the dominant person or group supersede the diversity in interests at Metis. A particular unit's proximity to top management can earn the unit perceived power and respect to 'dictate' an agenda that is aligned with that of the senior management. "It is often said that major change is impossible unless the head of the organisation is an active supporter" (Kotter, 1995:62). Organisations do not reflect monolithic cultures despite the likelihood that organisational cultural values may be restricted to the espoused values of senior management. They bear multiple interpretations. 
Change efforts in practice also show that commonly promoted learning exercises do not address radically different ways of doing things whereby underlying assumptions are challenged. The research findings indicate that resource constraints put pressure on individuals to seek immediate returns, inhibiting efforts to engage in radically different learning exercises. Learning is considered as effective when an impact can be observed at the operational level. "Learning for learning's sake is good, and it is even better if you have an actual impact at the bottom line" (Training Manager at Samson). Radically different ways of doing things, which are generally generated by double-loop learning, are seen as initiated by external consultants rather than by internal change agents. This finding is in line with Argyris and Schön's (1978) argument that organisations can manage single-loop learning (that is learning through feedback on actions rather than assumptions) themselves but require outside intervention for double-loop learning. According to the Chief Executive of Metis, "some sort of crisis helps. It focuses the mind wonderfully". He argues that "once you have started the process, if you achieve a few successes and demonstrate that the process is working, that is a very motivating factor".

The politicised nature of change management is also reflected by the lobbying efforts of Samson and Metis. The cases indicate that power is found in relational structures that involve networks or coalitions competing for resources. The financial strength of a stakeholder determines the shift of power among coalitions. An inquiry into the triggers of change revealed that a stakeholder influence is as significant as a structural or technical environmental change in the initiation of organisational change. A Samson engineer argues that "a lot of time is spent building relations, for one needs to 'buy in' the 
influential people". This is especially applicable to the environmental programme members. They need to work with the local authority to influence public opinion. By the same token, Metis needs to work closely with three key partners, namely the training councils, engineering federations and the government (see Figure 1).

\section{Insert Figure 1 About Here}

The lobbying efforts of Metis take the form of using the appropriate discourse and networking with the influential stakeholders. In the short term, Metis meets the expectation of the government. In the long term, it attempts to satisfy the needs of the industry (Regional Manager at Metis).

A paradox is encountered where internal change agents acknowledge and make transparent their perceptions and expectations concerning management of organisational change. Internal change agents attempt to act proactively and influence change. At the same time, they commonly confront situations where they do not have enough time, capital or information to undertake a formal strategic analysis of all possible alternatives. This points to the value of dialectical thinking where change is perceived as a holistic phenomenon that exhibits many interconnected facets of activities (Calori et al., 2000).

\section{CONCLUSION}

The case study findings show that the contingencies that are seen as providing an optimum solution for organising labour, raw materials and capital and for adopting new 
organisational practices by the advocates of the rational-linear view of organisational change (e.g.Kotter, 1995) only serve as internal change agents' espoused beliefs. In practice, the impact of a change-inducing contingency can vary across organisations. In spite of the fervour surrounding rational-linear models of change, there is evidence to suggest that firms are not as uniform in the manner in which they respond to change. As the present study shows, there are cultural and political factors at play that can result in persistent differentiation across organisations.

The differences in perceptions of what change management means and how it happens are likely to be important in influencing behaviour. For example, where a change agent adopts a rational, planned view, he or she is likely to limit considerable freedom to particular individuals and follow an orderly linear approach to change management. However, as the systemic-multivariate accounts of change management in this study indicate, organisations are not simply driven to incorporate practices and procedures defined by prevailing rationalised concepts of organised work.

In an ideal sense, change from within an organisation may be seen as sufficient to initiate change in mindsets. However, in practice, internal change agents, as far as the cases are concerned, require discontinuous change evoked by an external stimulus to initiate change in mindsets. Organisational members tend not question the status quo unless they are faced with an obligatory change factor, such as a financial or a political crisis. For instance, small evolutionary changes at Samson are not strong enough to undermine the old system. It is difficult to break habitual routines that are embedded in past learning. 
What appears to be needed to encourage people to accept change is the unfreezing of the organisation by 'disconfirming, and creating anxiety and psychological safety' (Schein, 1993) and institutionalising new behaviours in a context of intuitive appreciation of the different challenges to profound change and contextual learning (Senge et al., 1999).

Although change in itself means uncertainty, managers are expected to generate clear and adequate formulation of what the problem is and where they would like the organisation to be. In other words, they are expected to create a coherent structure from a set of incoherent and disorderly events. Although, in theory, common values and preferences can allow for clarity in direction, in practice, resource constraints and power struggles do not provide one with the flexibility to work towards a complete agreement of organisational decisions and goals.

The idealised normative patterns of change agents are clearly different from the nonrational perspective that is actively pursued in practice. Internal change agents' perceptions about the need for change, the opportunity to change and about the way to change are vital aspects to be understood. An area that merits further research is the process whereby organisations can achieve a healthy balance between the systemicmultivariate realities and the rationalised normative qualities of the business world in managing change. This would constitute a step towards a more refined research on organisational change and help contribute to developing better conceptual frameworks that take a more integrated view and improve managerial practice. 


\section{REFERENCES}

Ackoff, R. L. (1993), "The art and science of mess management", in Mabey, C. and Mayon-White, B. (Eds.), Managing Change, Pail Chapman Publishing, London, pp. 4754.

Argris, C. and Schön, D. (1978), Organisational Learning, Addison-Wesley, Massachusetts.

Boje,D. M. (2001), Narrative Methods for Organisational \& Communication Research, Sage Publications, London.

Bridges, W. (1995), Managing Transitions: Making the Most of Change, Nicholas Brealey Publishing Ltd., London.

Buchanan, D. A. (1993), "Review of a strategy of change: Concepts and controversies in the management of change", Journal of Management Studies, Vol 30, No 6, pp. 684-86.

Buchanan, D. A. and Badham, R. (1999), "Politics and organisational change: The lived experience", Human Relations, Vol 52, No 5, pp. 609-29.

Buchanan, D. A. and Boddy, D. (1992), The Expertise of the Change Agent, PrenticeHall, London.

Burns, T. and Stalker, G. M. (1961), The Management of Innovation, Tavistock, London.

Calori, R., Baden-Fuller, C. and Hunt, R. (2000), "Managing change at Novotel: Back to the future", Long Range Planning, Vol 33, No 6, pp. 779-804.

Carnall, C. (1995), Managing Change in Organisations, Prentice-Hall International, Hemel Hempstead.

Church, A. H., Burke, W. W. and Eynde, D. F. van (1994), "Values, motives and interventions of organisation development practitioners", Group and Organisation Management, Vol 19, No 1, pp. 5-50.

Cooperrider, D. L. and Bilimoria, D. (1993). "The challenge of global change for strategy: Opportunities for charting a new course", in Shrivastava, A. H. and Dutton, J. (Eds.), Advances in Strategic Management: Responding to a Changing World, Vol 9, JAI, Greenwich, Connecticut, pp. 99-142.

Dawson, S. (1996), Analysing Organisations, $3^{\text {rd }}$ edition, Macmillan Education Ltd., London.

Dunphy, D. C. and Stace, D. A. (1993), "The strategic management of corporate change", Human Relations, Vol 46, No 8, pp. 905-20. 
French, W. L. and Bell, C. H. Jr. (1990), Organisation Development: Behavioural Science Interventions for Organisation Improvement, $4^{\text {th }}$ edition, Prentice-Hall, Englewood Cliffs, New Jersey.

Glaser, B. G. and Strauss, A. (1967), The Discovery of Grounded Theory of Structure, Aldine Publishing Co, Chicago, Illinois.

Goodstein, L. D. and Burke, W. W. (1991), "Creating successful organisation change", Organisation Dynamics, Vol 19, pp. 5-17.

Hammond, S. A. (1996), The Thin Book of Appreciative Inquiry, The Thin Book Publishing Co, Plano, Texas.

Hartley, J., Benington, J. and Binns, P. (1997), "Researching the roles of internal-change agents in the management of organisational change", British Journal of Management, Vol 8, No 1, pp. 61-73.

Hassard, J. (1991), "Multiple paradigms and organisational analysis: A case study", Organisation Studies, Vol 12, No 2, pp. 275-99.

Huberman, A. M. and Miles, M. B. (1998), "Data Management and Analysis Methods", in Denzin, N. K. and Lincoln, Y. S. (Eds.), Collecting and Interpreting Qualitative Materials, Sage Publications, Thousand Oaks, California, pp. 179-210.

Kanter, R. M., Stein, B. A. and Jick, J. D. (1992), The Challenge of Organisational Change: How Companies Experience it and Leaders Guide it, Free Press, New York.

Knights, D. and Willmott, H. (1995), "Culture and control in a life insurance company", Studies in Cultures, Organisations and Societies, Vol 1, No 1, pp. 29-46.

Kotter, J. P. (1995), "Leading change: Why transformation efforts fail", Harvard Business Review, March-April, pp. 59-67.

Marshak, R. J. (1993), "Managing the metaphors of change", Organisational Dynamics, Vol 22, No 1, pp. 44-56.

Miles, R. H. (1997), Leading Corporate Transformation: A Blueprint for Business Renewal, Jossey-Bass Publishers, San Francisco.

Nonaka, I. and Takeuchi, H. (1995), The Knowledge-creating Company: How Japanese Companies Create the Dynamics of Innovation, Oxford University Press, New York.

Paton, R. A. and McCalman, J. (2000), Change Management: A Guide to Effective Implementation, $2^{\text {nd }}$ edition, Sage Publications, London.

Pettigrew, A. M., Ferlie, E. and McKee, L. (1992), Shaping Strategic Change. Sage Publications, London. 
Reed, M. (1992), The Sociology of Organisations, Harvester Wheatsheaf, Hertfordshire.

Schein, E. H. (1993), "How organisations learn faster? The challenge of entering the green room", Sloan Management Review, Winter, pp. 85-92.

Senge, P. (1990), "The leader's new work: Building learning organisations", $\underline{\text { Sloan }}$ Management Review, Vol 32, No 1, pp. 7-23.

Senge, P., Kleiner, A., Roberts, C., Ross, R., Roth, G. and Smith, B. (1999), The Dance of Change: The Challenges of Sustaining Momentum in Learning Organisations, Doubleday, New York.

Senior, B. (1997), Organisational Change, Financial Times Pitman Publishing, London.

Sturdy, A. and Morgan, G. (2000), "From transformation to financialisation? - Towards a discursive approach to organisational change and a structural approach to discourse", paper presented at the APROS Conference, Sydney, Australia, July.

Tichy, N. M. (1983), Managing Strategic Change, John Wiley and Sons, New York.

Tushman, M. L., Newman, W. H. and Romanelli, E. (1997), "Convergence and upheaval: Managing the unsteady pace of organisational evolution", in Tushman, M. L. and Anderson, P. (Eds.), Managing Strategic Innovation and Change: A Collection of Readings, Oxford University Press, New York, pp. 583-94.

Weick, K. E. (1995), Sensemaking in Organisations, Sage, Newbury Park, California.

Wilson, D. C. (1992), A Strategy for Change: Concepts and Controversies in the Management of Change, Routledge, London. 


\section{ENDNOTES}

[1] Some of the interview questions were as follows: i) if you had the absolute power to change the company, what would it be? ii) what enables and blocks your change efforts? iii) how are decisions regarding change made and implemented? Who implements them? iv) what makes Samson/Metis a learning organisation?

[2] It is claimed that the 'atmosphere' across sites can vary from 'depressive' to 'can do' (IT manager at Samson). 


\section{Figure 1. The Stakeholder Network of Metis Authority}

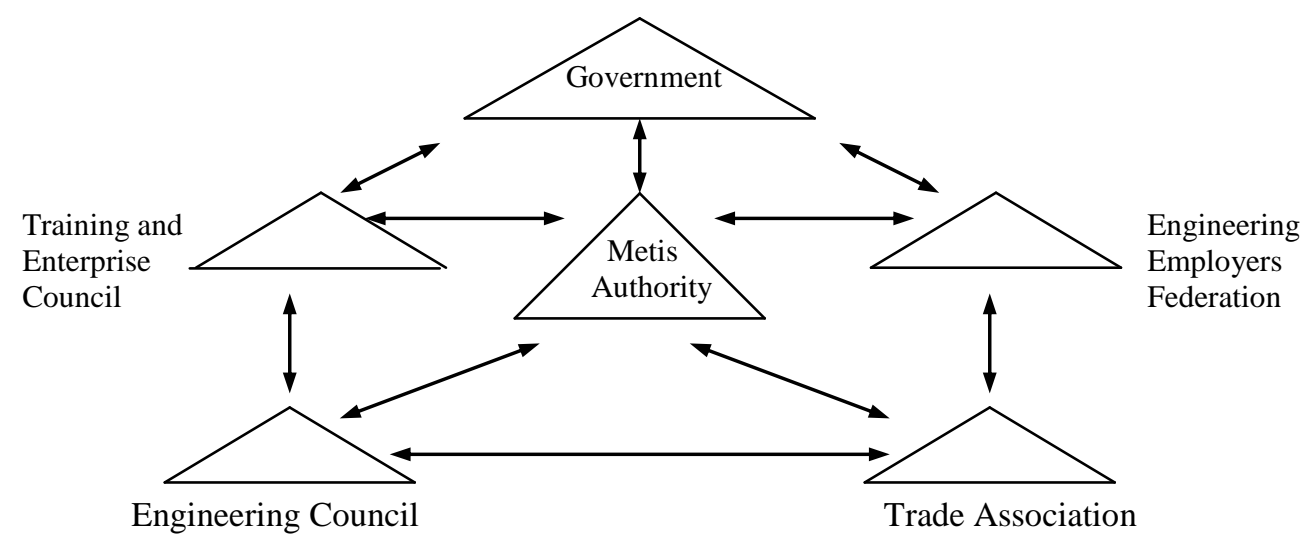

N.B.: The triangle nodes in this figure represent neither an exhaustive list nor the level of influence exerted by each stakeholder. 